\title{
Gêneros textuais e ensino de produção escrita: um caso de ensino do francês em nível universitário
}

\author{
Eliane GOUVÊA LOUSADA * \\ University of Guelph - Canadá
}

Resumo: Este artigo tem por objetivo apresentar uma experiência de ensino de produção escrita para estudantes universitários de Francês como língua segunda baseada em gêneros textuais. Esta experiência foi realizada em um curso de francês para alunos anglófonos da Universidade de Guelph, Canadá. O programa do curso foi baseado nos pressupostos teóricos do Interacionismo sociodiscursivo (BRONCKART, 2006; 2007; 2008) e também nos trabalhos que exploram o uso de gêneros textuais para o ensino de língua materna (SCHNEUWLY; DOLZ, 2004) e estrangeira (CRISTÓVÃO, 2002). Os resultados foram bastante positivos, mas apontaram a necessidade de algumas modificações para o melhor aproveitamento dos alunos.

Palavras-chave: Gêneros textuais; Arquitetura textual; Capacidades de linguagem.

\begin{abstract}
This paper aims at presenting an experience of teaching based on the teaching of written production for undergraduate students based on textual genres. This experiment was carried out in a French Course for English speakers at the University of Guelph. The curricula of the course were based on the theoretical

\footnotetext{
* Doutorado em Linguística Aplicada e Estudos da Linguagem pela Pontifícia Universidade Católica de São Paulo (2006). Docente da University of Guelph, Canadá, no departamento de Etudes Françaises, ministrando aulas no nivel da graduação, mestrado (Masters) na área de didática do francês, tendo exercido a função de orientadora. Contato: elousada@uoguelph.ca.
} 
framework of the Sociodiscursive interactionism by Bronckart (2006; 2007; 2008). Studies that use genres of texts within the teaching of first and second languages were also used as references (SCHNEUWLY; DOLZ, 2004; CRISTOVÃO, 2002). The results were quite interesting, but pointed out the need of some changes in order to increase the learning of the target language.

Key-words: Textual genres; Textual architecture; Language capacities.

\section{Introdução}

Este artigo tem por objetivo apresentar uma experiência de ensino de produção escrita para estudantes universitários de Francês como segunda língua ${ }^{1}$ baseada em gêneros textuais. Trata-se de um curso ministrado por mim e por uma Assistente ${ }^{2}$ para os cursos de francês na Universidade de Guelph, Canadá, no primeiro semestre 2008.

Como sabido, o Canadá é um país oficialmente bilíngue, tendo o francês e o inglês como línguas oficiais. Porém, exceto a única província em que o francês é a primeira língua, o Québec, nas outras províncias o inglês é a língua mais usada, apesar da existência de inúmeras comunidades francófonas em várias partes do país. A aprendizagem do francês é possibilitada, na escola, por meio de vários sistemas, sobretudo o das classes de imersão, em que os alunos têm aulas de francês como parte do currículo. Além disso, existem várias oportunidades para aperfeiçoar o nível de língua, através de cursos de francês diretamente em províncias e/

\footnotetext{
${ }^{1}$ FLS: francês como língua segunda, designa uma língua que tem estatuto particular, quer seja social e/ou político, como no caso do francês nas províncias anglófonas do Canadá. A LS pode ser também a língua da escolarização e, em ambos os sentidos, diferencia-se das outras línguas estrangeiras.

2 Teacher assistant: TA. Em 2007/2008, Laetitia Fabre.
} 
ou regiões francófonas patrocinados pelo governo canadense, com bolsas de estudos. Após o contato menos ou mais bem sucedido com o francês na escola, os alunos têm a possibilidade de escolher matérias relacionadas ao francês quando entram na faculdade. Sendo assim, no nível da graduação, são oferecidos cursos de francês em vários níveis, desde principiantes até níveis mais avançados, centrados na produção oral ou na produção escrita, passando por vários cursos de literatura francesa e quebequense. Apesar de serem oferecidos cursos para iniciantes, é importante lembrar que, no Canadá, os alunos são raramente verdadeiros principiantes em francês como o são em outras línguas, já que têm vários conhecimentos sobre essa língua aprendidos ao longo da escolaridade. Da mesma forma, os alunos de segundo e/ou terceiro ano têm mais conhecimento do que o esperado nesses níveis em outros contextos.

Neste artigo, vamos abordar o caso do curso de francês para produção escrita, oferecido aos alunos de terceiro ano universitário, que têm essa matéria como obrigatória. Foi nesse curso que pude fazer uma experiência de elaboração de um currículo para ensino de gêneros textuais escritos em francês, posto em aplicação no primeiro semestre do ano de 2008. Para apresentar esta experiência, dividimos esse artigo em quatro partes: primeiramente a fundamentação teórica que embasou tanto a elaboração do programa quanto sua aplicação em sala de aula; em seguida, a apresentação detalhada do contexto de estudo e do programa utilizado, seguida da análise dos resultados obtidos. Finalmente, passaremos à apresentação das considerações finais.

\section{Pressupostos Teóricos}

Este estudo, desde a elaboração do programa do curso até sua aplicação em sala de aula, está baseado nos pressupostos teóricos do interacionismo sociodiscursivo (BRONCKART, 2006; 2007; 2008), sobretudo no que diz respeito à questão dos gêneros textuais e às características linguístico-discursivas dos textos. Além disso, baseamo-nos também nos trabalhos sobre utilização de 
gêneros textuais para aprendizagem de língua materna (francês) no contexto da Suíça francófona (SCHNEUWLY; DOLZ, 2004) e para o ensino de português como língua materna no Brasil (MACHADO, 2001; MACHADO; ABREU-TARDELLI; LOUSADA, 2004a; 2004b; 2005; 2007). Utilizamos, sobretudo, as aplicações dessa perspectiva teórica para língua estrangeira, principalmente em suas realizações no Brasil (CRISTÓVÃO, 2002; DAMIANOVIC, 2006; LOUSADA, 2002a; 2002b; 2006; ABREUTARDELLI, 2006).

Um dos conceitos teóricos a partir do qual nosso programa de curso foi montado é a noção de gênero como proposta por Bakhtin (1953) e retomada por Bronckart (2006; 2007; 2008). Para Bakhtin (1953), a cada tipo de atividade humana que implica o uso da linguagem correspondem enunciados particulares, os gêneros do discurso. Bronckart retoma essa concepção de gênero, propondo a terminologia gênero de texto e guardando para o termo discurso outro significado. ${ }^{3}$ Esse autor salienta, ainda, que a linguagem é constituída de práticas situadas, ou seja, a atualização da linguagem por indivíduos em situações concretas. Essas práticas situadas são chamadas por Bronckart $(2008$, p. 87 ) de agir linguageiro que, por sua vez, se traduz em um texto. Dentro dessa perspectiva teórica, o texto seria visto como

[...] toda unidade de produção verbal que veicula uma mensagem organizada e que visa a produzir um efeito de coerência sobre o destinatário, ou, então, como uma unidade comunicativa de nível superior, correspondente a uma determinada unidade de agir linguageiro. (BRONCKART, 2008, p. 87)

Para Bronckart (2008, p. 88), os gêneros de textos estão presentes no arquitexto de uma comunidade linguageira, tendo sido construídos pelas gerações precedentes e organizados em um

\footnotetext{
${ }^{3}$ Ver Bronckart (2006; 2008).
} 
repertório de modelos. Assim, o falante de uma língua tem a seu dispor uma série de modelos textuais e vai escolher ("adotar") o mais apropriado a determinada situação que se caracteriza por uma série de parâmetros físicos (emissor, receptor, espaço-tempo do ato de produção) e sociossubjetivos (tipo de interação social em curso, objetivos possíveis nesse quadro, papéis atribuídos aos protagonistas da interação). Dessa forma, o texto produzido terá sempre características genéricas, provenientes da adoção de um modelo do arquitexto, e características individuais, provenientes de escolhas individuais em função da situação de produção (BRONCKART, 2008, p. 88).

Ainda segundo Bronckart (2007), a partir da situação de produção, o falante / enunciador / textualizador vai organizar seu texto segundo os três níveis da arquitetura textual. O primeiro nível diz respeito à infraestrutura textual, subdividida em dois regimes de organização: a planificação geral do conteúdo temático, ou seja, a ordem dos conteúdos temáticos que aparecem no texto, como um resumo, e os tipos de discurso, referentes à construção de mundos discursivos. Os tipos de discurso podem ser entendidos como pertencentes a dois eixos principais: narrar e expor. O eixo do narrar - disjunção pode ser implicado ou autônomo, ou seja, pode apresentar ou não implicação em relação ao ato de produção (através de dêiticos espaciais, temporais e de pessoa). O eixo do expor - conjunção - pode também ser implicado ou autônomo. Sendo assim, dentro desses dois eixos, há outra divisão que dá origem aos tipos de discurso: narrar - disjunto e autônomo (tipo de discurso narração); narrar - disjunto e implicado (tipo de discurso relato interativo) e expor - conjunto e implicado (tipo de discurso interativo) e expor - conjunto e autônomo (tipo de discurso teórico). ${ }^{4}$

\footnotetext{
${ }^{4}$ Para maiores explicações sobre os tipos de discurso, ver Bronckart (2006; 2008).
} 
Ainda no nível da infra-estrutura textual, Bronckart (2007) baseia-se em Adam e propõe outra forma de planificação que são as sequências. Diferentemente dos tipos de discurso, essas sequências podem ou não estar presentes, aparecem geralmente combinadas (é difícil encontrar em um texto uma só sequência) e dividem-se em: narrativa, descritiva, argumentativa, explicativa, injuntiva e dialogal. Além disso, Bronckart (2007) apresenta o grau zero da sequência narrativa, onde não há intriga, tensão, que seria o script e o grau zero das sequências argumentativa e explicativa, a esquematização, onde não há a necessidade de explicar algo de difícil compreensão ou argumentar em favor ou contra algo que pode ser contestável. ${ }^{5}$

Para Bronckart (2007), o segundo nível da arquitetura textual é constituído dos mecanismos de textualização, que é caracterizado pela coerência e pela coesão. A primeira diz respeito às relações entre os níveis de organização de um texto e é explicitada pelos organizadores textuais. A segunda pode ser divida em coesão nominal e verbal.

No terceiro nível da arquitetura textual, encontramos os mecanismos de responsabilidade enunciativa que dão a coerência pragmática do texto (BRONCKART, 2007). Nesse nível, encontramos a questão das modalizações, responsáveis pelas diversas avaliações do falante/enunciador/textualizador sobre um ou outro aspecto do conteúdo temático. Encontramos também a questão das vozes que explicitam as instâncias que assumem ou se responsabilizam pelo que está sendo dito.

Voltando à questão dos gêneros textuais, podemos dizer que, enquanto que os gêneros são relativamente estáveis, os textos que os materializam são extremamente variáveis e maleáveis (BRONCKART, 2006; SCHNEUWLY; DOLZ, 2004), o que torna difícil a sua classificação. Assim, como cada situação de uso da língua se realiza verbalmente por meio de um gênero, podemos

\footnotetext{
${ }^{5}$ Para maiores explicações sobre as fases das sequências, ver Bronckart (2007).
} 
concluir que a capacidade de comunicação depende do maior ou menor domínio (DOLZ; SCHNEUWLY, 1996) que se tem do gênero em questão, mesmo quando se trata de língua materna (LM). Evidentemente, enquanto construções sociais e históricas, muitos gêneros podem ser mais ou menos dominados pelos locutores nativos de uma língua. Uma carta formal, mesmo em língua materna, pode ser um gênero de difícil realização para muitos falantes adultos, enquanto que uma conversa para comprar algo em uma loja pode ser mais fácil para a maioria dos falantes adultos, em língua materna, uma vez que se trata de um gênero bastante usado no cotidiano. Já em língua estrangeira, é necessário que os alunos aprendam a compreender e produzir textos pertencentes a gêneros mais ou menos conhecidos / mais ou menos parecidos com suas realizações em LM, dado que as sociedades contemporâneas do mundo ocidental apresentam, muitas vezes, textos com características semelhantes.

Dessa forma, procuramos, em nosso programa, selecionar gêneros que pudessem ser de algum interesse para os alunos, baseando-nos nos seguintes critérios propostos por Schneuwly \& Dolz (1998) e expostos por Cristóvão (2002, p. 97):

a) a dimensão psicológica, incluindo as motivações, a afetividade e os interesses dos alunos;

b) a dimensão cognitiva, refletindo a complexidade do tema e o estatuto do conhecimento dos alunos;

c) a dimensão social, envolvendo a densidade social do tema, suas potencialidades polêmicas, a relação entre eles e os participantes, os aspectos éticos, sua presença real no interior ou no exterior da escola e a possibilidade de, com ela, se desenvolver um projeto de classe;

d) a dimensão didática, que demanda que o tema não seja excessivamente cotidiano, mas que possa ser apreensível.

Em relação ao item $a$, procuramos fazer uma escolha de gêneros que pudessem ser motivantes e interessantes para uma classe que tinha alunos com idade média de 20 a 24 anos. Buscamos, dessa forma, selecionar temas de textos que pudessem agradar a essa faixa etária de alunos. Por exemplo, quando o gênero escolhido era um guia turístico, escolhemos uma cidade francófona canadense; 
para a biografia, foram escolhidos autores francófonos, dentre os quais alguns canadenses; para a produção escrita de sinopse e resenha crítica de filme, foram escolhidos filmes atuais. Além disso, para o artigo de opinião, foi escolhido um texto ligado à questão da ecologia que desperta grande interesse na região. Para a carta do leitor, foi escolhido um pequeno texto sobre a universidade em Toronto. Em relação ao item $b$, por se tratar de alunos do terceiro ano de francês na faculdade, que tinham um bom nível de língua, em geral, foram escolhidos gêneros mais complexos materializados em textos que envolvem mais conhecimento linguístico. Devido ao grande interesse dos alunos dessa universidade e dos canadenses, em geral, pelo tema da ética e da ecologia, foram escolhidos textos e gêneros que propiciaram o debate sobre esses temas em sala de aula, criando polêmicas e discussões, atendendo, assim, ao critério c. No que diz respeito ao item $d$, é necessário salientar que se tratava do ensino de língua segunda e não língua materna. Sendo assim, como o francês é uma língua estrangeira para os alunos e não a LM, os gêneros escolhidos podiam até ser cotidianos para eles, porém em inglês e não em francês.

A partir desses critérios de escolha dos gêneros a serem trabalhados, podem ser propostos agrupamentos de gêneros, em função de suas características tipológicas dominantes, que são, para Schneuwly \& Dolz (2004): narrar, relatar, argumentar, expor, descrever ações (sequências injuntivas) e que podem ser compreendidas a partir da infra-estrutura textual (tipos de discurso e sequências) descrita acima.

Além do gênero como unidade de ensino a partir da qual o programa será organizado, adotamos também a noção de gênero como ferramenta que atua no processo de aprendizagem (SCHNEUWLY; DOLZ, 2004, p. 28.). Nessa segunda abordagem, o gênero seria encarado como um verdadeiro megainstrumento mediador entre o sujeito e a situação. $\mathrm{O}$ gênero textual, enquanto megainstrumento, contribuiria para o desenvolvimento dos três tipos de capacidades de linguagem: as de ação, as discursivas, as linguístico-discursivas. Segundo Dolz, Pasquier e Bronckart (1993) e Dolz e Schneuwly (1998), ao interagirmos nas diferentes situações sociais por meio dos textos que produzimos, fazemos uso dessas 
capacidades, que estão diretamente ligadas aos três níveis da arquitetura textual propostos por Bronckart $(2006$; 2007) e explicitada acima. As primeiras envolvem a mobilização das representações do produtor sobre o contexto de produção do texto. As capacidades discursivas envolvem as operações de organização textual do texto a ser produzido, de escolha de um ou vários tipos de discurso e a escolha do modo de organização sequencial. As últimas, as capacidades linguístico-discursivas, envolvem os aspectos linguísticos propriamente ditos, incluindo várias operações de textualização (como, por exemplo, a operação de assegurar a coesão textual, verbal e/ou nominal) e operações enunciativas (como, por exemplo, o gerenciamento de vozes e a modalização dos enunciados).

O trabalho em sala de aula se constituiria, pois, em compreender e produzir textos, pertencentes a diferentes gêneros, visando a desenvolver nos alunos as capacidades descritas acima. Para tanto, podemos trabalhar a partir de agrupamentos de gêneros e desenvolvimento de uma sequência de atividades que constituem a sequência didática ( $\mathrm{SD}$ ). Embora de maneira sucinta, apresentaremos, a seguir, os gêneros escolhidos e a sequência didática proposta para desenvolver essas capacidades.

\section{O Programa de Curso e o Contexto de Estudo}

Como já mencionado, a experiência que relatamos neste artigo foi conduzida junto a uma turma de francês como segunda língua do terceiro ano universitário, em uma província anglófona do Canadá. Tratava-se de uma classe de 50 alunos, de faixa etária entre 19 e 26 anos, em geral. ${ }^{6}$ Os alunos tinham níveis bastante heterogêneos de francês, desde alunos praticamente bilíngues (francês e inglês), até alunos que ainda têm alguma dificuldade com a escrita e mesmo a fala em francês. O curso durou 12 semanas, sendo dividido em 3 aulas de 50 minutos por semana.

\footnotetext{
${ }^{6}$ Dois alunos da terceira idade também assistiram ao curso.
} 
Levando em conta os critérios expostos anteriormente para a escolha dos gêneros textuais a serem trabalhados, foram escolhidos os seguintes gêneros para desenvolvimento com os alunos:

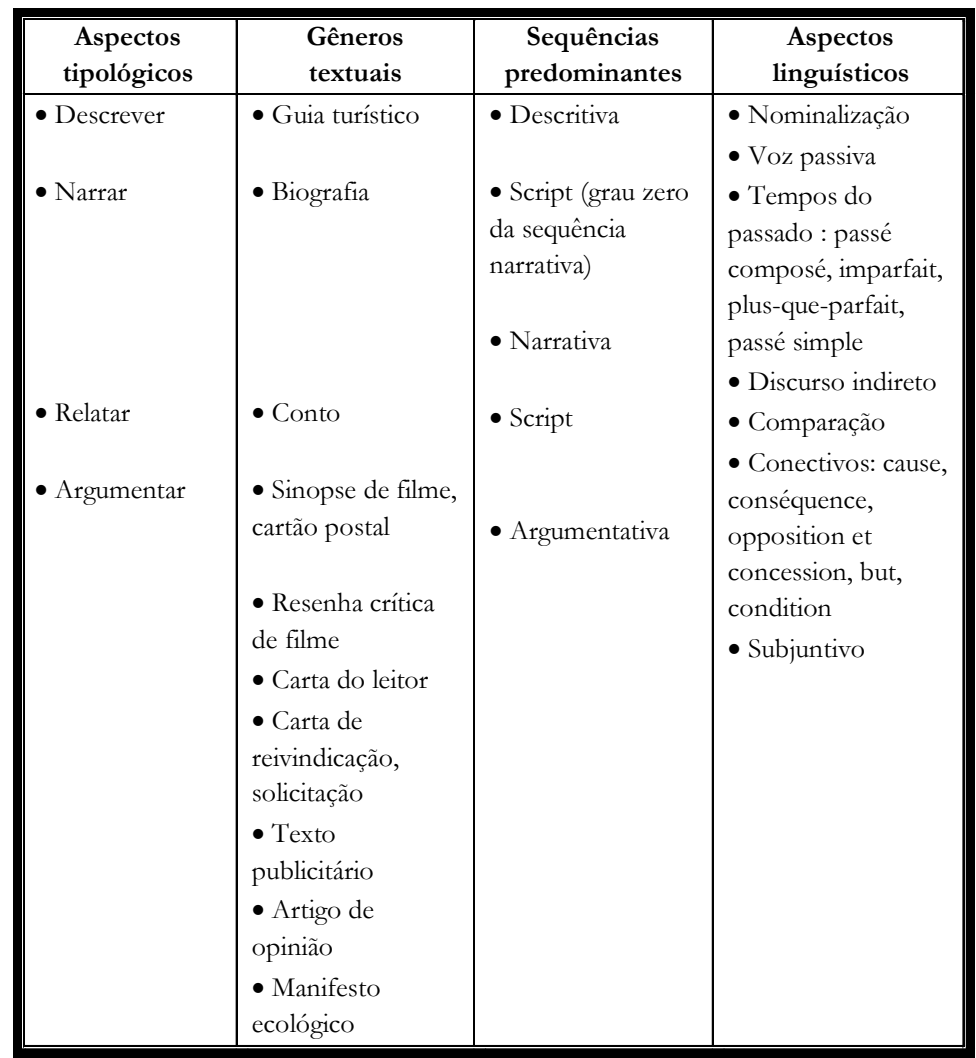

Quadro 1 - aspectos tipológicos, gêneros escolhidos, sequências predominantes e aspectos linguísticos ${ }^{7}$

\footnotetext{
${ }^{7}$ Neste quadro, as três primeiras colunas apresentam uma sequência/ ordem dos conteúdos e podem ser lidas horizontalmente. A quarta coluna apresenta os aspectos linguísticos sem ordem específica, pois podem corresponder a um ou mais gêneros.
} 
Para o trabalho em sala de aula, foram estabelecidos critérios para uma sequência didática compatíveis com o tipo de curso, número de alunos em sala de aula e número de horas disponíveis para o curso. Isso incluía discussões em sala de aula para verificação do conhecimento de mundo sobre o gênero a ser trabalhado e também pequenas produções orais e escritas que objetivavam preparar os alunos para a produção final. Dentro das limitações de termos muitos alunos e poucas horas de aulas, não foram realizadas produções iniciais, pois optamos por começar diretamente pela análise de um texto pertencente ao modelo de gênero que tínhamos a intenção de trabalhar. Além disso, cabe dizer que as produções foram, em sua maioria, realizadas em grupo. Sendo assim, propusemos as seguintes etapas da SD, apresentadas aqui de maneira esquematizada: ${ }^{8}$

1. Apresentação da situação de produção: as representações dos alunos sobre as várias situações de ação de linguagem que podem dar origem ao texto pertencente ao gênero em questão;

2. Primeiro contato com o gênero: análise da situação de ação de linguagem que deu origem ao texto escolhido como modelo do gênero e comparação com as respostas ao item 1;

3. Análise do texto em relação ao aspecto tipológico dominante, à(s) sequência(s) predominante(s) e aos aspectos linguísticos característicos;

4. Atividades para desenvolver os aspectos tipológicos dominantes, as sequências predominantes e/ou os aspectos linguísticos característicos, segundo as dificuldades dos alunos;

\footnotetext{
${ }^{8}$ Para uma apresentação da sequência didática típica para trabalho com gêneros, ver Schneuwly \& Dolz (2004).
} 
5. Atividades visando a dar o input necessário para a produção final do texto. Por exemplo, no caso da redação de um conto, as atividades foram relacionadas à reconstituição dos contos conhecidos dos alunos e de seus elementos mais característicos. No caso da redação da carta de reivindicação e do manifesto ecológico, os alunos assistiram a vídeos on-line abordando questões ecológicas que permitiram melhor conhecer o tema e a situação de ação de linguagem;

6. Produção do texto final, em grupos de dois ou três alunos;

7. Indicação dos erros pelo professor e pela assistente, através de uma legenda disponível para os alunos na plataforma on-line blackboard, ${ }^{9}$ levando em conta erros relacionados ao gênero e erros relacionados à língua. Nota provisória, até a segunda correção, baseada em critérios de correção descritos mais à frente;

8. Refacção do texto, pelos alunos;

9. Correção pelo professor e pela assistente, com modificação na nota em função das correções.

Além das etapas acima descritas, os erros mais frequentes eram anotados e, ao término da escrita de um gênero de texto, uma série de 10 a 12 erros mais frequentes era impressa e distribuída aos grupos para correção em sala de aula. Durante essa atividade, os alunos eram levados a refletir sobre o erro, deviam propor sua correção e a explicação da regra subjacente.

\section{As Produções Analisadas}

Junto com a assistente para o curso, foi determinado que cada produção escrita final realizada seria avaliada segundo os critérios a seguir:

${ }^{9}$ Cada curso e cada classe dispõem de um espaço na plataforma blackboard onde estão disponíveis os documentos importantes para o curso. 
- Adequação ao gênero ${ }^{10}$

- Escolha dos conteúdos temáticos

- Coesão e coerência

- Aspectos sintáticos

- Aspectos lexicais

Em função dos critérios acima, podemos dizer que os textos mais bem escritos e mais adequados ao gênero foram: a biografia, o guia turístico, o conto e o texto publicitário. A carta do leitor, a carta de reivindicação, o cartão postal e o manifesto ecológico podem ser considerados como mais ou menos adequados ao gênero. Em relação ao artigo de opinião, podemos dizer que a adequação ao gênero variou muito de aluno para aluno, assim como o manifesto ecológico. No caso do artigo de opinião, o maior problema encontrado foi relacionado à questão dos tipos de discurso usados, mais especificamente ao eixo da implicação / autonomia dos parâmetros da interação. Na verdade, nesse gênero textual, não é comum a implicação dos parâmetros da interação ao texto, como fizeram muitos alunos. Em outras palavras, foi usada a primeira pessoa do singular para mostrar a opinião própria, sem levar em conta que se tratava de um artigo de opinião para uma revista ou jornal em que o jornalista não expressa sua opinião em primeira pessoa. Já a sinopse e a resenha crítica de filme, ficaram bem aquém do que era esperado dos alunos. Os maiores problemas desses dois gêneros textuais foram: em alguns casos, a menção à situação em que foram ao cinema para assistir ao filme, ou seja, novamente a implicação dos parâmetros da interação no texto, o que não é uma característica do gênero; a enorme interferência do inglês na maneira de formular os enunciados. $\mathrm{Na}$ verdade, foi o gênero de texto em que a língua materna mais interferiu.

\footnotetext{
${ }^{10}$ Embora a adequação ao gênero apareça formalmente apenas no primeiro item, todos os outros itens também foram analisados em relação à adequação ao gênero.
} 
Para tentar entender a diferença nos resultados das produções textuais, procuramos rever o processo de escrita de cada um dos gêneros e pudemos observar o seguinte:

- Os quatro gêneros de textos mais bem escritos foram os gêneros mais bem trabalhados em termos de análise do modelo de gênero. Em outras palavras, trata-se dos gêneros que foram desenvolvidos durante mais aulas, com muitos recursos audiovisuais e com os quais os alunos mais se envolveram;

- Os quatro gêneros que tiveram resultado médio quanto ao nível das produções dos alunos foram gêneros razoavelmente bem trabalhados em sala de aula, em termos de análise do modelo de gênero;

- Em relação aos dois gêneros que apresentaram mais disparidades no nível das produções dos alunos, pudemos observar que o artigo de opinião foi razoavelmente bem compreendido pelos alunos que vieram frequentemente às aulas. Porém, como não havia um único modelo do gênero e, já que vários artigos foram trabalhados na fase final do curso, talvez tenha faltado um modelo mais canônico para muitos alunos, que acabaram tendo dificuldades em visualizar o que era pedido com o artigo de opinião. Em relação ao manifesto ecológico, tratou-se do último texto escrito em aula. Sendo assim, embora todo o contexto sobre ecologia tenha sido bem explorado, não houve tanto tempo para analisar manifestos ecológicos e os alunos também já estavam um pouco cansados;

- Em relação à sinopse e à resenha crítica de filme, os textos em que os alunos tiveram mais dificuldade de produzir um texto adequado ao gênero, pudemos constatar, em primeiro lugar, a falta de tempo (por problemas alheios ao cronograma) para melhor analisar várias sinopses e resenhas críticas de filme. Além disso, 
este pareceu ser um gênero que os alunos dominavam bastante bem em inglês. Dessa forma, talvez pelo fato de conhecerem bem o gênero em inglês e de não terem tido tempo para analisar melhor o gênero em francês, as produções tenham tido tantas características das formulações em inglês;

- Além disso, no que diz respeito aos erros mais frequentes trabalhados com os alunos, podemos dizer que alguns deles foram corrigidos pelos alunos em suas produções finais, porém muitos deles foram esquecidos, talvez pela grande quantidade de erros frequentes ressaltados.

A partir das observações acima, propomos, em seguida, uma reflexão sobre os resultados obtidos e sobre as mudanças necessárias para o próximo semestre do curso, visando a obter melhores resultados.

\section{Considerações Finais}

Em primeiro lugar, é importante mencionar que a atitude dos alunos em relação ao curso foi muito boa. Em geral, os alunos interessaram-se bastante pelo curso e fizeram muitos elogios ao tipo de curso e de atividades. ${ }^{11}$ Por esta razão e pelos resultados das produções, em sua maioria satisfatórios, podemos dizer que o curso teve sucesso de modo geral. Sendo assim, devem ser mantidos, em nossa opinião: o trabalho baseado em gêneros textuais, alguns dos gêneros textuais escolhidos, o trabalho sobre os erros frequentes e as correções dos alunos, a reescrita do texto, o recurso a outras atividades, recursos audiovisuais, entre outros,

\footnotetext{
${ }^{11}$ Isso foi atestado nas avaliações entregues pelos alunos no final do curso, que demonstraram um bom grau de satisfação com a metodologia e o conteúdo do curso.
} 
visando a dar mais dinamismo ao curso. Esse último item contribuiu também para criar um ambiente de imersão no tema a ser tratado, e mesmo no gênero textual a ser escrito, que motivou bastante os alunos para a escrita e, talvez por isso, resultou em produções melhores.

No entanto, a partir das observações apresentadas anteriormente, parece-nos importante salientar também a necessidade de efetuar algumas mudanças para assegurar um melhor nível de produções e um melhor aproveitamento do semestre em geral. Em primeiro lugar, parece-nos importante elaborar um programa de curso em que haja tempo suficiente para o trabalho com os diferentes gêneros, ainda que menos gêneros sejam abordados. Nesse sentido, seria necessário mais tempo para analisar o texto usado como modelo do gênero a ser trabalhado, para que os alunos possam aprender as características do gênero e também suas realizações linguísticas em francês. Segundo os resultados obtidos, a análise minuciosa do modelo de gênero a ser produzido parece-nos ser de vital importância para a verdadeira aprendizagem, sobretudo por se tratar de uma língua outra que a língua materna. Um dos pontos a ressaltar é a importância de trabalhar melhor os tipos de discurso, a criação de mundos discursivos, sobretudo a implicação e autonomia em relação à situação de ação de linguagem (interação), já que a autonomia não foi respeitada nas sinopses, resenhas críticas e artigos de opinião. Além disso, seria necessário mais tempo para as correções linguísticas e para a refacção do texto, sem o que, a aprendizagem, tanto do gênero textual, quanto dos aspectos linguísticos, não atinge o nível que poderia atingir.

De qualquer forma, a escolha de um programa baseado em gêneros textuais visando à aprendizagem da produção escrita em uma segunda língua parece ter sido uma proposta bastante interessante e adequada para este público de produção escrita de francês em nível universitário. 


\section{Referências}

ABREU-TARDELLI, Lília Santos. Elaboração de seqüências didáticas: ensino aprendizagem de gêneros em língua inglesa. In: DAMIANOVIC, Maria Cristina. Material didático: elaboração e avaliação. Taubaté: Cabral, 2006.

BAKHTIN, Mikhail. Estética da criação verbal. 2. ed. São Paulo: Martins Fontes, 1997 [1953].

BRONCKART, Jean-Paul. Atividade de linguagem, discurso e desenvolvimento humano. Campinas: Mercado de letras, 2006.

Atividade de linguagem, textos e discursos: por um interacionismo sociodiscursivo. 2. ed. São Paulo: Educ, 2007.

O agir nos discursos: das concepções teóricas às concepções dos trabalhadores. Campinas: Mercado de Letras, 2008.

CRISTOVÃO, Vera Lúcia Lopes. O gênero quarta capa no ensino do inglês. In: DIONISIO, Angela Paiva; MACHADO, Anna Rachel; BEZERRA, Maria Auxiliadora. Gêneros textuais \& ensino. Rio de Janeiro: Lucerna, 2002. p. 95-106.

DAMIANOVIC, Maria Cristina. Material didático: elaboração e avaliação. Taubaté : Cabral, 2006.

DOLZ, Joaquim; PASQUIER, Auguste; BRONCKART, Jean-Paul. L'acquisition des discours: emergence d'une competence ou apprentissage de capacities langagières? Études de Linguistique Appliquée, n. 92, p. 23-37, 1993.

; SCHNEUWLY, Bernard. Genres et progression en expression orale et écrite: éléments de réflexions à propos d'une expérience romande. Enjeux, 37/38, 1996, p. 49-75.

Pour un enseignement de l'oral : initiation

aux genres formels à l'école. Paris: ESF, 1998. 
LOUSADA, Eliane. La notion de 'genre': une contribution à la compréhension et à la production de textes. Synergies Brésil, v. 3, p. 90-97, fev. 2002a.

Elaboração de material didático para o ensino de francês. In: In: DIONISIO, Angela Paiva; MACHADO, Anna Rachel; BEZERRA, Maria Auxiliadora. Gêneros textuais \& ensino. Rio de Janeiro : Lucerna, 2002b. p. 73-86.

O texto como produção social. In: DAMIANOVIC, Maria Cristina. Material didático: elaboração e avaliação. Taubaté: Cabral, 2006.

MACHADO, Anna Rachel. Um instrumento de avaliação de material didático com base nas capacidades de linguagem a serem desenvolvidas no aprendizado de produção textual. Intercâmbio, v. X, p. 137-147, 2001.

.; ABREU-TARDELLI, Lília Santos; LOUSADA, Elaine Gouvêa. Resumo. São Paulo: Parábola, 2004a.

\begin{tabular}{l} 
___ Resenha. São Paulo: Parábola, 2004b. \\
\hline Paulo: Parábola, $2005 . \quad$. Planejar gêneros acadêmicos. São
\end{tabular} .; ___ Trabalhos de pesquisa: diários de leitura para a revisão bibliográfica. São Paulo: Parábola, 2007.

SCHNEUWLY, Bernard; DOLZ, Joaquim. Gêneros orais e escritos na escola. Campinas: Mercado de Letras, 2004. 